\title{
A pediatric case developing critical abdominal distension caused by a combination of humidified high-flow nasal cannula oxygen therapy and nasal airway
}

\author{
Satoki Inoue*, Yumiko Tamaki, Shota Sonobe, Junji Egawa and Masahiko Kawaguchi
}

\begin{abstract}
Background: We describe a pediatric patient who suffered from critical abdominal distention caused by a combination of humidified, high-flow nasal cannula (HHFNC) oxygen therapy and nasal airway.

Case presentation: A 21-month-old boy with a history of chronic lung disease was admitted to the intensive care unit (ICU). Immediately after admission, his airway was established using a tracheal tube and mechanical ventilation was started. Five days after the commencement of mechanical ventilation, finally, his trachea was extubated. Immediately after extubation, HHFNC therapy at $20 \mathrm{~L} /$ min with an $\mathrm{FiO}_{2}$ of 0.35 was applied. However, severe stridor was observed, then a nasal airway was placed in the left nostril. However, he became restless. Critical abdominal distention was observed. A subsequent chest X-ray revealed that the nasal airway was placed too deeply, and the gastrointestinal air was severely accumulated. Immediately, the nasal airway was removed, and HHFNC flow was reduced to $10 \mathrm{~L} / \mathrm{min}$. Frequent suctioning and continuous gastric drainage were required, which achieved gradual improvement of respiratory condition.
\end{abstract}

Conclusions: We need to recognize that HHFNC therapy is one of the positive pressure ventilation system. Therefore, HHFNC therapy might cause the similar adverse events to noninvasive pressure ventilation.

Keywords: Humidified, High-flow nasal cannula, Abdominal distention, Nasal airway, Complication, Pediatric patient

\section{Background}

Humidified, high-flow nasal cannula (HHFNC) oxygen therapy has allowed optimal humidification of inspired gas at high flows, which could create a distending pressure-like nasal continuous positive airway pressure (CPAP) [1]. There is a small but growing body of information from clinical trials that support the use of HHFNC as an alternative oxygen interface for critically ill patients across the entire age spectrum, from premature neonates to adults [2-4]. In addition, it has been reported that HHFNC is equivalent to more traditional non-invasive ventilation support, such as continuous or bi-level positive airway pressure (CPAP or BiPAP) [3, 4]. Therefore, HHFNC has become a popular and easy

\footnotetext{
* Correspondence: seninoue@naramed-u.ac.jp

Department of Anesthesiology and Division of Intensive Care, Nara Medical University, 840 Shijo-cho Kashihara, Nara 634-8522, Japan
}

respiratory option for pediatric patients despite the lack of clear practical guidance for safety operation. We describe a pediatric patient who suffered from critical abdominal distention caused by a combination HHFNC therapy and nasal airway.

\section{Case presentation}

The consent of patient's next of kin was obtained; however, institutional review board approval was exempted because neither the ethical problem nor the description to identify the patient was included in this case report. A 21-month-old boy with acute or chronic lung disease was admitted to the intensive care unit (ICU). He was $63 \mathrm{~cm}$ in height and weighed $7.9 \mathrm{~kg}$. He was bone on the $24^{\text {th }}$ week of gestation and weighed $645 \mathrm{~g}$ and had been provided with home oxygen therapy with $3 \mathrm{~L} / \mathrm{min}$ oxygen administration. His chest computed tomography
Springer Open

(c) The Author(s). 2018 Open Access This article is distributed under the terms of the Creative Commons Attribution 4.0 International License (http://creativecommons.org/licenses/by/4.0/), which permits unrestricted use, distribution, and reproduction in any medium, provided you give appropriate credit to the original author(s) and the source, provide a link to the Creative Commons license, and indicate if changes were made. 
showed several giant bullae in the bilateral lungs (Fig. 1). He had gastroesophageal reflux and an intestinal feeding tube $(6.5 \mathrm{~F})$ and a gastric drainage tube $(6 \mathrm{~F})$ indwelled.

He had been suffering from upper respiratory infection and fever for a couple of days. He gradually developed hypoxia $\left(\mathrm{SpO}_{2}<90 \%\right)$ with oxygen administration. Immediately after admission, his airway was established using a cuffed $3.5-\mathrm{mm}$ tracheal tube. Immediately after the beginning of mechanical ventilation, $10-\mathrm{cm} \mathrm{H}_{2} \mathrm{O}$ positive end-expiratory pressure (PEEP) combined with moderate pressure support $\left(8 \mathrm{~cm} \mathrm{H}_{2} \mathrm{O}\right)$ was applied.

His respiratory status gradually improved. Five days after the commencement of mechanical ventilation, finally, his trachea was extubated. Immediately after extubation, HHFNC therapy at $20 \mathrm{~L} / \mathrm{min}$ with an $\mathrm{FiO}_{2}$ of 0.35 (Optiflow system ${ }^{\mathrm{ms}}$, MR850 heated humidified RT202 delivery tubing; Fisher and Paykel Healthcare Ltd., Auckland, New Zealand) was applied through nasal cannula (Optiflow ${ }^{\text {Tx }}$ Junior Nasal Cannula Infant; Fisher \& Paykel, Auckland, New Zealand).

However, severe stridor because of upper airway obstruction was observed, then a 10-cm-long $3.5-\mathrm{mm}$ hand-made nasal airway (Portex ${ }^{\mathrm{Tw}}$, Smith Medical, Kent, UK) was placed in the left nostril $(10 \mathrm{~cm}$ depth). It was not confirmed whether or not inserting the tube too deeply because he violently resisted being checked with a laryngoscopy. But, stridor or retractive breathing was not observed. Therefore, HHFNC therapy was restarted with this airway position.

HHFNC was conducted smoothly for a while; however, he became restless and then started agonizing heavily with $\mathrm{SpO}_{2}$ reduction down to $70 \%$. Critical abdominal distention was observed, and forced gastric drainage was

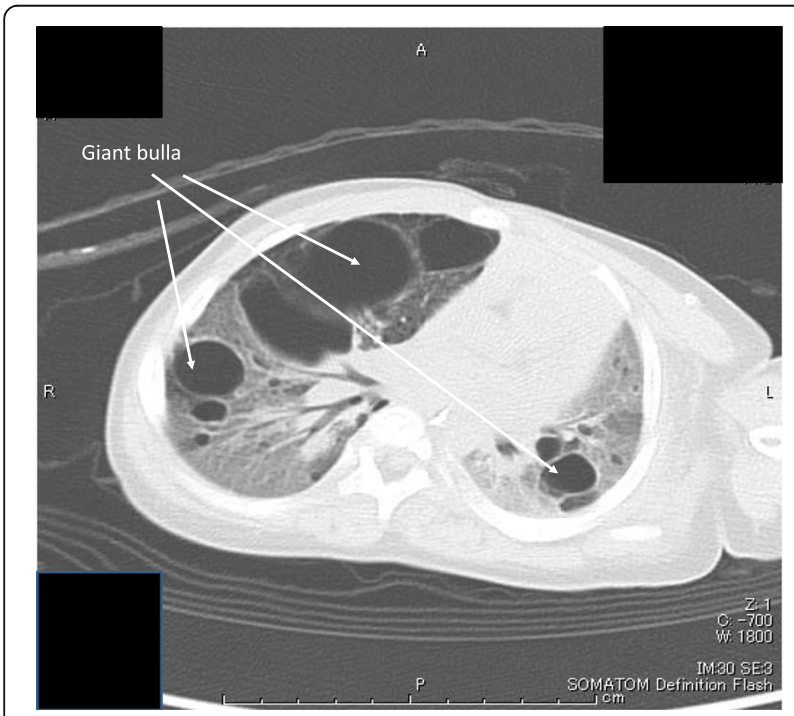

Fig. $1 \mathrm{~A}$ chest $\mathrm{CT}$ at healthy status. Several giant bullae in the bilateral lungs were observed started through a gastric tube. However, the critical situation was not improved. A subsequent chest X-ray revealed that the nasal airway was placed too deeply (Fig. 2), and the gastrointestinal air was severely accumulated (Fig. 3).

Immediately, the nasal airway was removed and HHFNC flow was reduced to $10 \mathrm{~L} / \mathrm{min}$. Frequent suctioning and continuous gastric drainage were required, which achieved gradual improvement of respiratory condition. Finally, HHFNC therapy was successfully terminated.

\section{Conclusions}

It is supposed that the deeply inserted nasal airway caused critical abdominal distention by insufflating the HHFNC flow into the gastrointestinal rather than the respiratory tract. In the early stage before the development of critical abdominal distention, the HHFNC flow might have partially supported his breathing; however, it is likely that the HHFNC flow gradually became ineffective for supporting his breathing because of aerophagia. In addition, his gastroesophageal reflux might have worsened the situation because aerophagia is possibly accelerated by noninvasive positive airway pressure in patients with gastroesophageal reflux [5]. Abdominal compartment syndrome related to noninvasive ventilation was also reported [6]. In a pediatric model, a linear relationship between flow and pressures measured in the pharynx (pressure $=-0.375+0.138 \times$ flow) with the closed-mouth condition was reported. According to this model, $2.4 \mathrm{~cm} \mathrm{H} \mathrm{H}_{2} \mathrm{O}$ of positive pressure was generated in our patient at that time. This low level of pressure might unusually force air into the stomach; however, the positive pressure drastically increased with a high nasal prong-to-nares ratio and mouth closed status [7]. Therefore, it might be a little wonder that a positive pressure

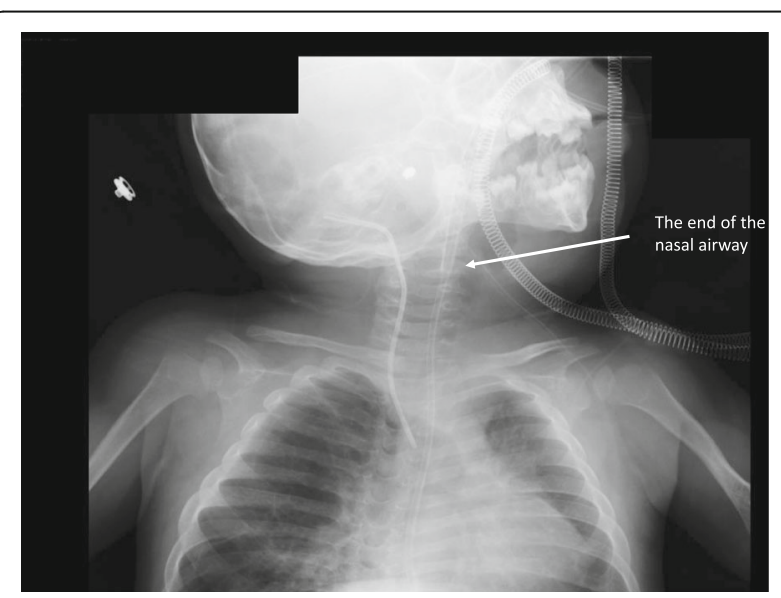

Fig. 2 A cervical X-ray at deteriorated respiratory status. A subsequent cervical X-ray revealed that the nasal airway was placed too deeply 


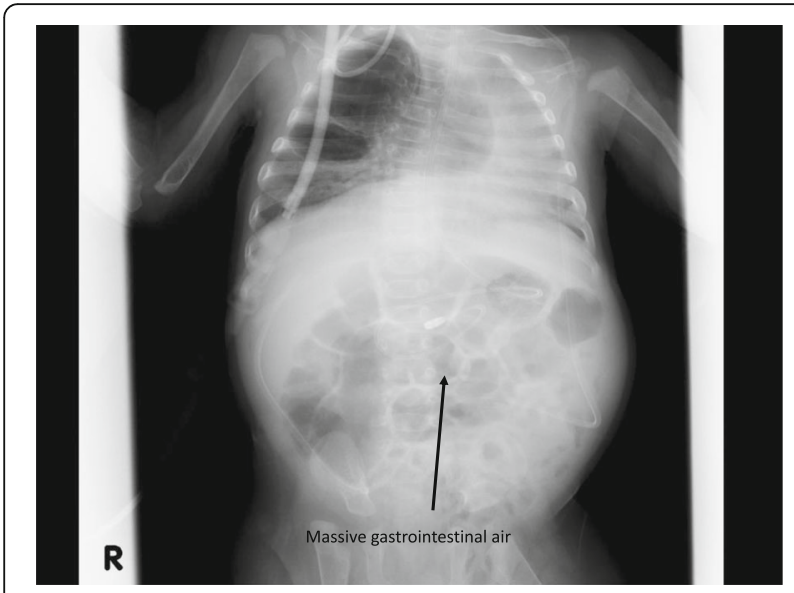

Fig. 3 A chest-abdominal X-ray at deteriorated respiratory status. A subsequent chest-abdominal $X$-ray revealed that gastrointestinal air was severely accumulated

high enough to open the esophageal sphincter was generated according to the circumstances, which caused the gastrointestinal overdistention. To confirm the location of the tip of the nasal airway, we could have used a fine fiberoptic bronchoscopy as an option. We should have carefully monitored the patient considering the development of this adverse event.

In conclusion, we need to recognize that HHFNC therapy is one of the positive pressure ventilation system. Therefore, HHFNC therapy might cause the similar adverse events to noninvasive pressure ventilation. This time, we would like to underline that critical abdominal overdistention could happen by HHFNC therapy.

\section{Abbreviations}

BiPAP: Bi-level positive airway pressure; CPAP: Continuous positive airway pressure; HHFNC: Humidified, high-flow nasal cannula; ICU: Intensive care unit; PEEP: Positive end-expiratory pressure

\section{Acknowledgements}

None

\section{Funding}

This study was supported only by the department.

\section{Availability of data and materials}

Not applicable

\section{Authors' contributions}

All authors were involved in the treatment of the patient. SI and YT collected the patient's data, drafted the manuscript, and obtained the consent for publication from the patient's next of kin. SS, JE, and MK revised and edited the manuscript. All authors contributed and approved the final version of this manuscript.

\section{Ethics approval and consent to participate}

The consent of patient's next of kin was obtained; however, institutional review board approval was exempted because neither the ethical problem nor the description to identify the patient was included in this case report.

\section{Consent for publication}

The consent for publication was obtained from the patient's next of kin.

\section{Competing interests}

The authors declare that they have no competing interests.

\section{Publisher's Note}

Springer Nature remains neutral with regard to jurisdictional claims in published maps and institutional affiliations.

Received: 20 December 2017 Accepted: 26 December 2017

Published online: 05 January 2018

\section{References}

1. Lampland AL, Plumm B, Meyers PA, Worwa CT, Mammel MC. Observational study of humidified high-flow nasal cannula compared with nasal continuous positive airway pressure. J Pediatr. 2009;154:177-82.

2. Kepreotes E, Whitehead B, Attia J, Oldmeadow C, Collison A, Searles A, Goddard B, Hilton J, Lee M, Mattes J. High-flow warm humidified oxygen versus standard low-flow nasal cannula oxygen for moderate bronchiolitis (HFWHO RCT): an open, phase 4, randomised controlled trial. Lancet. 2017; 389:930-9.

3. Frat JP, Thille AW, Mercat A, Girault C, Ragot S, Perbet $\mathrm{S}$, Prat G, Boulain T, Morawiec E, Cottereau A, Devaquet J, Nseir S, Razazi K, Mira JP, Argaud L, Chakarian JC, Ricard JD, Wittebole X, Chevalier S, Herbland A, Fartoukh M, Constantin JM, Tonnelier JM, Pierrot M, Mathonnet A, Béduneau G, Delétage-Métreau C, Richard JC, Brochard L, Robert R, FLORALI Study Group; REVA Network. High-flow oxygen through nasal cannula in acute hypoxemic respiratory failure. N Engl J Med. 2015:372:2185-96.

4. Kotecha SJ, Adappa R, Gupta N, Watkins WJ, Kotecha S, Chakraborty M. Safety and efficacy of high-flow nasal cannula therapy in preterm infants: a meta-analysis. Pediatrics. 2015;136:542-53.

5. Shepherd K, Hillman D, Eastwood P. Symptoms of aerophagia are common in patients on continuous positive airway pressure therapy and are related to the presence of nighttime gastroesophageal reflux. J Clin Sleep Med. 2013;9:13-7

6. De Keulenaer BL, De Backer A, Schepens DR, Daelemans R, Wilmer A, Malbrain ML. Abdominal compartment syndrome related to noninvasive ventilation. Intensive Care Med. 2003;29:1177-81.

7. Sivieri EM, Gerdes JS, Abbasi S. Effect of HFNC flow rate, cannula size, and nares diameter on generated airway pressures: an in vitro study. Pediatr Pulmonol. 2013;48:506-14.

\section{Submit your manuscript to a SpringerOpen ${ }^{\mathcal{O}}$ journal and benefit from:}

- Convenient online submission

- Rigorous peer review

- Open access: articles freely available online

- High visibility within the field

- Retaining the copyright to your article

Submit your next manuscript at $>$ springeropen.com 